\title{
PELATIHAN PENYUSUNAN SOAL BERBASIS KOMPUTER MENGGUNAKAN WQC
}

\author{
Akbar Nasrum ${ }^{1}$ \\ ${ }^{1}$ Program Studi Pendidikan Matematika Fakultas Keguruan dan Ilmu Pendidikan Universitas \\ Sembilanbelas November Kolaka \\ e-mail: akbar.nasrum30@gmail.com
}

\begin{abstract}
Abstrak
Tujuan utama dari pengabdian ini adalah berbagi ilmu pengetahuan kepada guru-guru di SMP Negeri 1 Tinondo tentang cara membuat instrumen soal online maupun offline, baik soal kuis, Ujian Tengah Semester ataupun Ujian Akhir Semester. Sebelum terjun ke lapangan, Tim PKM melakukan observasi di sekolah setempat dan melakukan wawancara dengan kepala sekolah tentang pembinaan apa saja yang diperlukan oleh guru-guru sekolah dalam rangka meningkatkan kemampuan diri mereka. Pelatihan pembuatan soal menggunakan software khusus ini merupakan salah satu dari beberapa hal yang dibutuhkan oleh pihak sekolah. Kegiatan yang dilaksanakan berlangsung sangat baik karena para peserta sangat antusias dengan apa yang kami berikan. Dari seluruh peserta yang hadir 16,67\% yang sangat paham dan sisanya $83,33 \%$ semuanya paham. Hasil nyata yang diperoleh setelah melakukan kegiatan pengabdian yaitu salah satu dari beberapa guru sekolah langsung menerapkan hasil pelatihan kepada siswa SMP untuk ujian tengah semester.
\end{abstract}

Kata Kunci: Wondershare, Soal, Berbasis Online

\section{A. Pendahuluan}

Perkembangan teknologi di era revolusi industri 4.0 saat ini membawa perubahan yang sangat besar dalam segala bidang. Semua pemangku kepentingan dalam setiap bidang harus bisa menyesuaikan perkembangan zaman agar tidak tertinggal. Dalam bidang pendidikan misalnya, ujian Nasional yang dulu dilakukan berbasis kertas perlahan-lahan mengalami perbaikan mulai dari ujian berbasis kertas yang diperiksa dengan sistem komputer hingga sekarang berubah menjadi ujian online. Ujian Akhir Semester pun demikian, walaupun belum semua sekolah namun saat ini sudah ada beberapa sekolah di Kabupaten Kolaka yang menerapkan ujian akhir berbasis online pada Ujian Akhir Semester.

Penerapan ujian berbasis online pada suatu sekolah tentu harus didukung oleh dua fasilitas utama yaitu tersedianya komputer dan jaringan. Kalau dua komponen ini tidak ada tentu ujian berbasis online tidak dapat dilaksanakan. Kendati demikian, tersedianya dua 
fasilitas itu bukan jaminan bahwa suatu sekolah pasti melakukan ujian secara online karena mungkin menurut mereka dibutuhkan tenaga ahli bidang komputer untuk mengembangkan ujian berbasis online. Padahal tidak demikian. Sekarang ada banyak fasilitas atau software yang dapat digunakan untuk mengembangkan instrumen soal berbasis online diantaranya Wondershare Quiz Creator (WQC), Ispring suite, Kahoot bahkan google drive pun dapat digunakan untuk membuat soal ujian secara online (Nasrum, 2020)

Ada satu sekolah di Kabupaten Kolaka Timur yang sangat ingin meningkatkan kualitas sekolah dan sumber daya manusia yang ada di dalamnya. Sekolah ini adalah SPM Negeri 1 Tinondo. Sekolah Menengah Negeri 1 Tinondo merupakan salah satu sekolah tingkat menengah yang berada di Ibu Kota Kecamatan Tinondo. Sejak berdirinya sekolah ini sudah dipimpin oleh empat orang kepala sekolah. Kepala sekolah terakhir yang menjabat sampai sekarang adalah Bapak Anton, S.Pd., M.Pd. Dibawah kepemimpinan beliau, sekolah ini dijadikan sekolah rujukan di Kab. Kolaka Timur. Kabupaten Kolaka Timur sendiri merupakan Kabupaten baru yang belum lama terbentuk.

Beberapa daerah di Kabupaten ini masih sangat sulit memperoleh jaringan seluler, apalagi jika ingin mengakses internet. Contohnya di daerah Tinondo, jaringan seluler timbul tenggelam, kadang ada dan kadang menghilang. Namun kondisi ini tidak menurunkan keinginan pemerintah daerah untuk terus meningkatkan mutu pendidikan. Baru-baru ini Dinas Pendidikan memberikan bantuan berupa komputer sebanyak 20 Unit di SMP Negeri 1 Tinondo agar dapat digunakan oleh siswa SMP untuk belajar Komputer.

Bukan hanya siswa, para guru juga dapat menggunakan fasilitas tersebut untuk berlatih memperdalam ilmu komputer mereka. Dengan adanya komputer ini, guru jangan lagi fokus hanya mengajar, tapi berusaha mengembangkan diri mencari informasi terbaru tentang pengetahuan dari sarana ini (Aisyah, 2011). Beberapa permintaan kepala sekolah terkait pelatihan-pelatihan yang dapat meningkatkan kompetensi para guru dan stafnya antara lain pelatihan penggunaan microsof excel, pelatihan pembuatan kelas online, pelatihan pembuatan soal ujian online dan lain-lain.

Melihat dan menyesuaikan kondisi pada bulan Maret yang lalu, mereka ingin mencoba melakukan ujian berbasis komputer via online. Ada beberapa pertimbangan mereka meminta pelatihan ini yaitu: Pertama, memberikan tambahan ilmu pengetahuan bagi guru dan stafnya; Kedua, menjadi contoh bagi sekolah-sekolah lain dalam meningkatkan kualitas 
pendidikan di Kecamatan Tinondo; Ketiga, bulan Maret merupakan masa-masa ujian tengah semester bagi siswa di SMP tersebut.

Selain pertimbangan itu, pihak sekolah juga sepakat bahwa ujian berbasis komputer, baik online maupun offline dapat mengurangi biaya produksi soal sehingga bisa menghemat sedikit anggaran (Dafitri, 2017). Ujian berbasis komputer juga bisa lebih transparan dalam hal pemberian nilai dan dapat meminimalisir kecurangan dalam ujian (Iqbal et al., 2018).

Olehnya itu kami memutuskan untuk turun ke lapangan memberikan pelatihan sebagaimana yang diminta yaitu "Pelatihan Penyusunan Soal Tes Berbasis Online dan Offline Menggunakan Software Wondershare Quiz Creator".

\section{B. Masalah}

Berdasarkan latar belakang di atas, rumusan masalah dalam pengabdian ini adalah: (1) Bagaimana tekis pelaksanaan Pelatihan di SMP Negeri 1 Tinondo?; (2) Apakah dengan adanya pelatihan ini proses ujian di SMP Negeri 1 Tinondo mengalami perubahan?

\section{Metode Pelaksanaan}

Metode yang digunakan dalam pengabdian ini adalah observasi, wawancara dan pelatihan. Observasi dilakukan setelah memperoleh beberapa info dari kepala sekolah tentang hal-hal yang dibutuhkan pihak sekolah. Dari hasil observasi yang dilakukan, pelatihan penyusunan soal berbasis online dan offline ini kemungkinan besar dapat terlaksana karena didukung oleh vasilitas yang memadai. Selanjutnya wawancara kami lakukan untuk memastikan pelaksanaan pengabdian dapat berjalan dengan lancar.

Sasaran pelaksanaan PKM adalah semua guru dan Staf yang ada di SMP Negeri 1 Tinondo. Kegiatan dilaksanakan pada bulan Maret 2020 selama dua Hari.

Langkah-langkah yang ditempuh dalam persiapan pelatihan antara lain sebagai berikut:

1. Memastikan semua komputer yang ada di Laboratorium telah terinstal Mozilla firefox dan adobe flash player.

2. Membuat vidio tutorial antara lain tutorial instalasi Wondershare quiz Creator dan cara menggunakan Wondershare quiz Creator untuk mempermudah proses pelatihan. 
3. Menyalin semua software yang dibutuhkan ke dalam google drive untuk dibagikan kepada peserta pelatihan. Untuk antisipasi bilamana jaringan tidak mendukung kami juga menyalinnya ke beberapa flashdisk.

\section{Pembahasan}

Indikator keberhasilan dari program pengabdian kepada masyarakat ini ada beberapa hal yaitu:

1. Banyaknya peserta yang mengikuti program pelatihan

2. Pemahaman materi pelatihan

3. Output/ luaran yang dapat dihasilkan setelah mengikuti pelatihan.

Karena komputer yang tersedia di laboratorium hanya ada 20 Unit maka target maksimal adalah 20 orang. Dalam pelaksanaan pelatihan jumlah peserta yang hadir ada 18 orang. Menurut kepala sekolah, dua orang lainnya tidak sempat hadir karena berhalangan. Kegiatan pelatihan dibuka oleh kepala sekolah SMP Negeri 1 Tinondo pada hari Sabtu dan Ahad tanggal 14 Maret 2020 pukul 09:00 WITA.

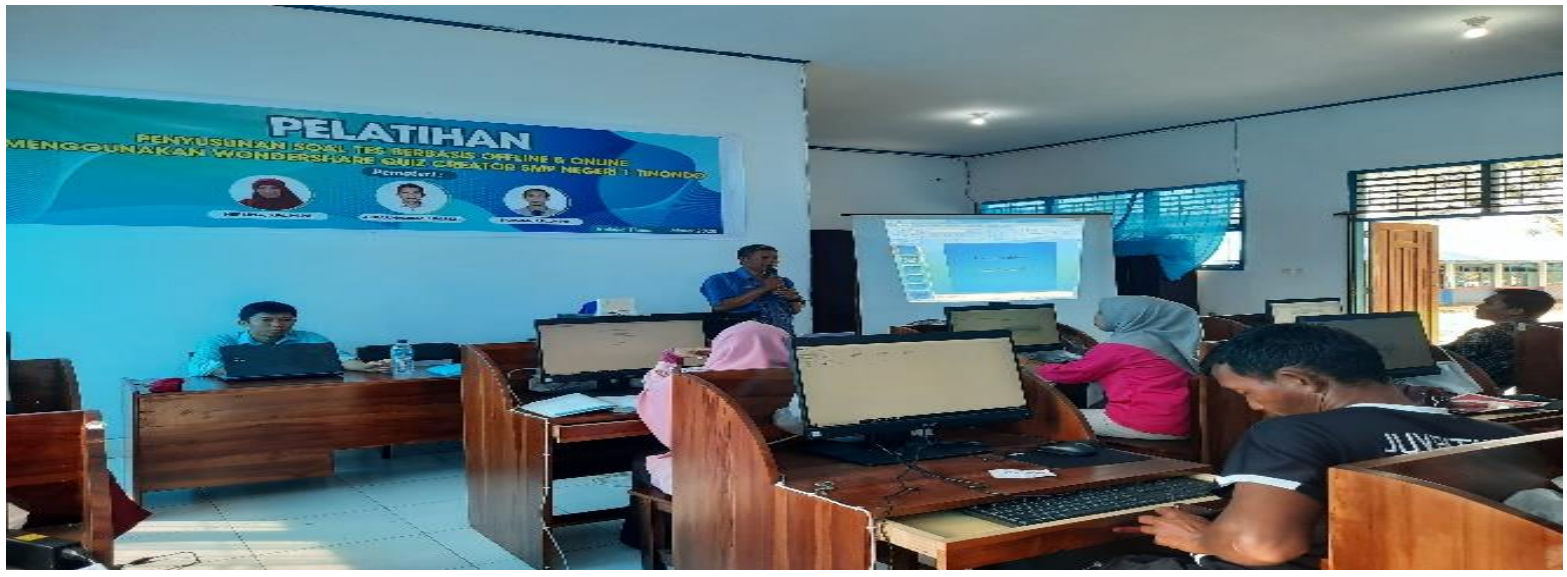

Gambar 1. Pembukaan Pelatihan Oleh Kepala Sekolah SMP 1 Tinondo

Setelah dibuka oleh Kepala sekolah, proses pelaksanaan pelatihan mulai dilaksanakan. Pertama-tama saya membawakan materi tentang keunggulan dari sistem evaluasi berbasis komputer. Setelah materi selesai saya jelaskan, selanjutnya software yang dibutuhan saya bagi ke seluruh komputer melalui komputer server. Proses pembagiannya cukup cepat karena menggunakan jaringan LAN. Setelah software terbagi selanjutnya saya memandu mereka untuk melakukan instalasi dan registrasi Wondershare Quiz Creator $(W Q C)$. Proses Instalasi dan registrasi berjalan lancar karena ada beberapa guru muda yang bisa menginstal sendiri dan membantu guru lain yang belum bisa. 

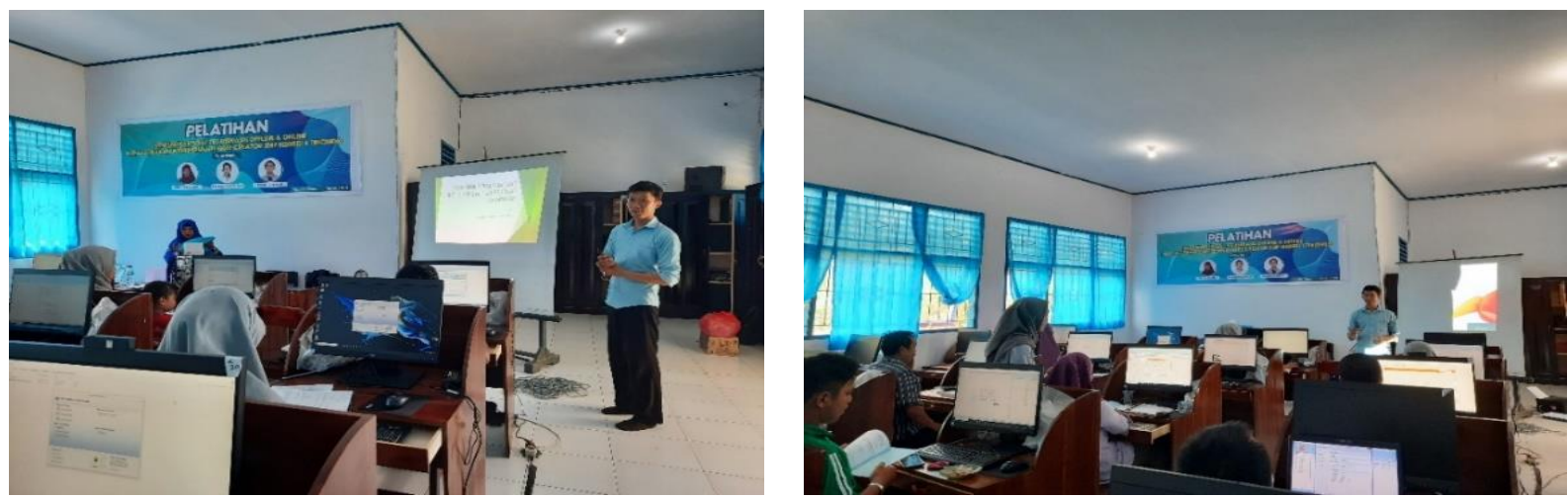

Gambar 2. Penjelasan Materi Tentang Evaluasi Berbasis Komputer

Selanjutnya setelah proses instalasi selesai saya mulai mengajak para guru untuk membuat soal berbasis komputer yang dapat digunakan tanpa jaringan (offline). Sebelumnya saya sudah menginformasikan sediakan soal-soal sesuai bidang studi masing-masing yang diampu. Namun saya lupa bahwa soalnya dalam bentuk file sehingga waktu yang seharusnya digunakan untuk mengimport soal ke aplikasi tersita untuk menulis kembali soal-soal tersebut.

Proses pelaksanaan pelatihan berlangsung dengan baik. Materi yang saya ajarkan dalam pelatihan ini antara lain sebagai berikut:

1. Peserta diajarkan bagaimana cara menginput soal dari word ke aplikasi, selain itu peserta juga diajarkan bagaimana cara membuat soal secara langsung menggunakan WQC.

2. Peserta diajar bagaimana mengatur tampilan soal seperti mengacak soal dan jawaban, menampilkan soal secara keseluruhan atau perhalaman, mengatur waktu pengerjaan, skor kelulusan, pemberian password pada aplikasi dan mempublish soal sehingga dapat digunakan secara offline maupun online.

Semua materi yang saya jelaskan mudah mereka pahami dan praktikkan. Jika ada kendala atau hal-hal yang tidak dimengerti dalam pelaksanaan latihan langsung saya jawab dengan memandu mereka satu persatu sehingga masalah langsung terselesaikan.

Hasil nyata dari pelatihan ini dapat dilihat pada gambar 3. Sehari setelah pelatihan dilaksanakan, seorang guru yang mengikuti pelatihan yaitu Bapak Irwan, S.P.di., M.Pd langsung menerapkan ujian berbasis komputer (offline) pada siswa SMP 1 Tinondo. Ini salah satu ukuran keberhasilan dari pelatihan yang kami laksanakan. Semoga semua guru yang mengikuti pelatihan dapat mengikuti jejak Bapak Irwan, S.P.di., M.Pd sehingga berangsurangsur ujian berbasis kertas dapat berubah menjadi ujian berbasis komputer. 


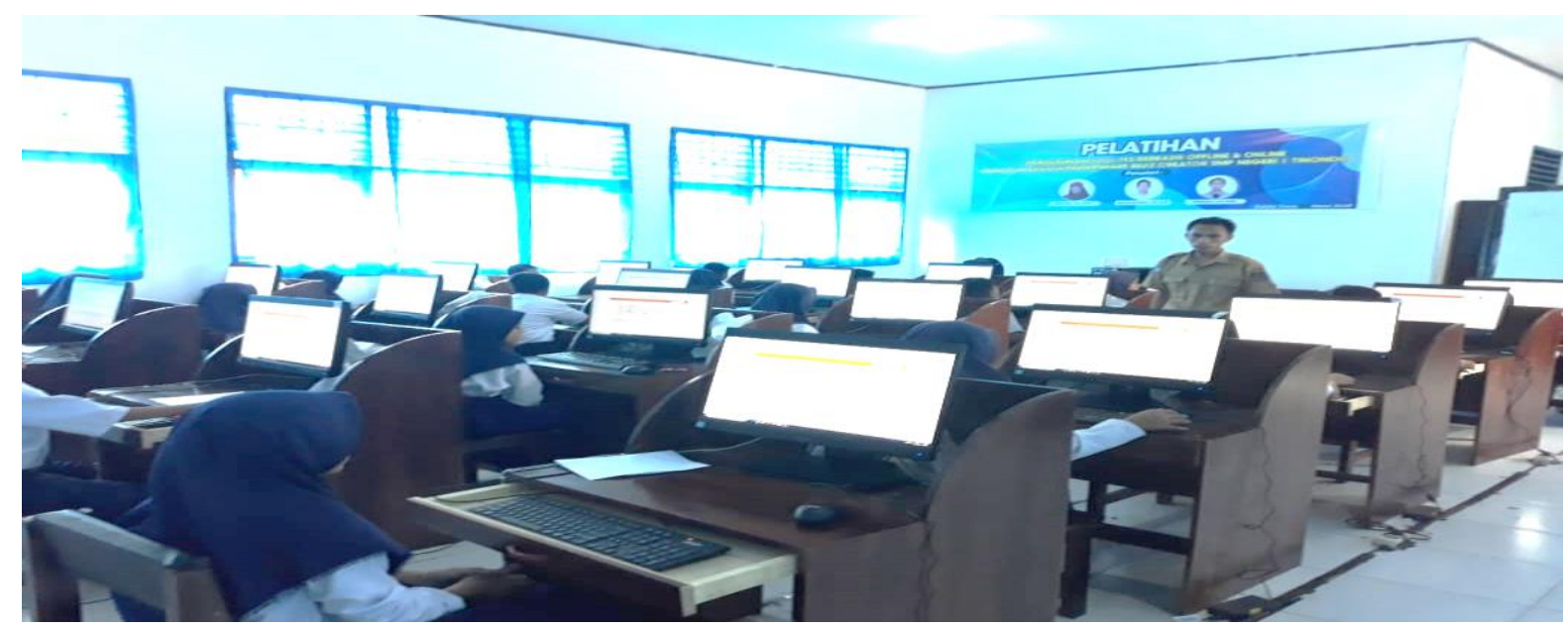

Gambar 3. Pelaksanaan Ujian Berbasis Komputer (offline) di SMP 1 Tinondo

Ada beberapa kendala yang tidak bisa kami atasi dalam pelaksanaan pelatihan ini sehingga tidak semua materi dapat disampaikan dalam pelatihan. Salah satu contohnya adalah materi tentang pembuatan soal online. Proses untuk menciptakan suatu aplikasi instumen soal dalam bentuk offline sudah diberikan namun bagaimana membuat aplikasi itu bisa digunakan secara online tidak dijelaskan dalam pelatihan karena masalah jaringan. Kami menunggu sejak saat pelatihan yang mulai di pagi hari sampai sore hari jaringan di Laboratorium komputer tidak mendukung sehingga materinya tidak tersampaikan.

Tidak tersampaikan dalam pelatihan bukan berarti materinya tidak diterima oleh peserta. Materi yang sempat disampaikan ataupun tidak disampaikan secara langsung dalam pelatihan sudah kami kemas dalam bentuk vidio tutorial sehingga walaupun tidak dijelaskan dalam pelatihan mereka tetap bisa mempelajarinya secara mandiri.

Secara keseluruhan dari dari delapan belas orang yang hadir, ada tiga orang yang sangat paham dengan materi pelatihan, salah satunya adalah Bapak Irwan. Sisa yang lima belas orang semuanya paham namun kadang-kadang masih perlu melihat vidio tutorial untuk mendapatkan petunjuk tentang langkah-langkah yang tidak diketahui. Harapan kami melalui vidio itu mereka bisa belajar dan mempraktikkan sendiri hingga dapat membuat suatu instrumen soal berbasis online dan dapat digunakan untuk ujian di SMP Negeri 1 Tinondo.

\section{E. Kesimpulan}


Kegiatan pengabdian masyarakat yang dilaksanakan dalam bentuk pelatihan untuk guru-guru berjalan sesuai dengan apa yang direncanakan sebelumnya. Ada beberapa kendala namun dapat teratasi dengan beberapa solusi yang sudah dipersiapkan. Jika para peserta terus mempelajari dan mengembangkan apa yang mereka dapat dari pelatihan maka tahun ajaran baru berikutnya tidak ada lagi ujian yang berbasis kertas.

\section{F. Ucapan Terimakasih}

Kami ucapkan terimakasih kepada Kepala Sekolah SMP Negeri 1 Tinondo selaku penanggung jawab kegiatan, kepada para TIM dan para guru peserta pelatihan. Suksesnya pelaksanaan pelatihan ini karena dukungan dari mereka semua.

\section{DAFTAR PUSTAKA}

Aisyah, S. (2011). Evaluasi Pembelajaran Berbasis IT dan Implikasinya terhadap Peningkatan Kualitas Pendidikan. Sosial Budaya, 8(1), 54-63. https://doi.org/10.24014/SB.V8I1.348

Dafitri, H. (2017). Pemanfaatan Wondershare Quiz Creator Dalam Tes Berbasis Komputer. QUERY: Jurnal Sistem Informasi, 01(01), 8-18.

Iqbal, W. M. G., Fadhilah, R., \& Hardiati, D. (2018). Pengembangan Alat Evaluasi Berbasis Wondershare Quiz Creator Pada Materi Koloid Kelas XI di SMA Koperasi Pontianak. Ar-Razi Jurnal Ilmiah, 6(1), 11-15.

Nasrum, A. (2020). Pengembangan Instrumen Evaluasi Pemahaman Konsep Kalkulus Berbasis Komputer. Histogram: Jurnal Pendidikan Matematika, 4(1), 79-92. https://doi.org/http://dx.doi.org/10.31100/histogram.v4i1.540 